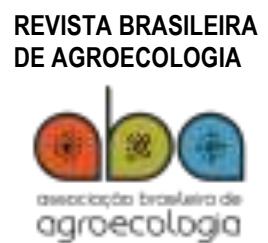

ISSN: 1980-9735

DOI: $10.33240 /$ rba.v15i5.22898

Vol. 15 | N0 5 | p.291-304 | 2020

ARTIGO

\title{
EXTRATIVISMO E GERAÇÃO DE RENDA DA MANGABA (Hancornia speciosa Gomes) EM REGIÃO LITORÂNEA DO RIO GRANDE DO NORTE
}

\author{
Extractivism and generation income with mangaba (Hancornia speciosa Gomes) in \\ the litoral region of Rio Grande do Norte
}

1 Doutoranda do Programa de Pós-Graduação em Desenvolvimento e Meio Ambiente, Universidade Federal do Rio Grande do Norte. E-mail: kiviaoliv@yahoo.com.br

2 Professor Adjunto do Departamento de Botânica e Zoologia, Universidade Federal do Rio Grande do Norte. E-mail: magdialoufal@gmail.com

Recebido em: 27/12/2018 Aceito para publicação em: 30/10/2020

Correspondência para: kiviaoliv@yahoo.com.br

\author{
Kívia Soares de Oliveira ${ }^{1}$, Magdi Ahmed Ibrahim Aloufa ${ }^{2}$
}

\section{RESUMO}

O extrativismo vegetal é uma prática frequente em regiões onde há espécies, potencialmente, úteis para a humanidade, devido ao seu caráter socioeconômico e cultural. Este estudo objetivou caracterizar o extrativismo da mangaba e avaliar o seu potencial de geração de renda no município de Nísia Floresta, RN. Realizaram-se entrevistas semiestruturadas, com perguntas sobre o perfil socioeconômico, coleta, comercialização e conhecimentos etnobotânicos associados ao extrativismo da mangaba. Os informantes locais possuem conhecimentos relacionados à mangabeira, são dependentes de seus recursos e percebem a sua diminuição. A redução das áreas nativas, o acesso limitado aos locais de coleta e as dificuldades de comercialização são os principais desafios para o desenvolvimento da atividade na região. A atividade gera renda média familiar de $\mathrm{R} \$ 3.314,08 / a n u a l$, porém, necessita de estratégias que integrem a conservação dos recursos genéticos e culturais, como programas de capacitação organizacional e implantação de uma associação para valorizar o produto.

Palavras-chave: Conhecimento local. Extrativismo vegetal. Produtos florestais não madeireiros.

\section{ABSTRACT}

Exploring plants is a practice frequent in regions where there are species potentially useful for humanity, due to their socioeconomic and cultural character. The objective of this study was to characterize the extraction of mangaba and to evaluate the potential for income in the municipality of Nísia Floresta, RN. Semi-structured interviews were applied, whit questions about the socioeconomic profile, collection, marketing, and ethnobotanical knowledge associated with the extraction of mangaba. Local informants have knowledge about the mangabeira, are dependent on their resources and perceive its decreasing. The reduction of the remaining areas of mangabeira, limited access to collection sites and the difficulties of commercialization are the main challenges for the development of extractivism in the region. The activity generates an average family income of $R \$ 3,314.08$ /annual. However, it needs strategies to integrate the conservation of genetic and cultural resources, such as organizational training programs and implementation of an association to value the product.

Keywords: Local knowledge. Plant extractivism. Non-timber forest products. 
Introdução

A exploração dos Produtos Florestais não Madeireiros (PFNM) vem sendo amplamente discutida como estratégia de garantir o manejo sustentável e a conservação da biodiversidade (FACHINELLO, 2010). No Nordeste do Brasil, o extrativismo de PFNM se destaca por ser atividade com potencial para produção sustentável e geração de renda e emprego, sobretudo, para populações que não possuem alternativas produtivas mais viáveis, mas que possuem acesso relativamente fácil aos recursos florestais (GAMA et al., 2017). Além disso, constitui uma importante estratégia para a segurança alimentar de populações de baixa renda.

Devido à intensa ocupação das áreas de vegetação nativa, muitas espécies da flora nativa, de uso direto para a humanidade, estão sendo levadas à extinção, em virtude da fragmentação dos seus habitats (OLIVEIRA, 2016). Estudos sobre o potencial de uso e manejo dessas espécies se tornam relevantes, já que o extrativismo de PFNM possui grande importância socioeconômica e cultural para muitas famílias do Nordeste, a exemplo da mangaba (Hancornia speciosa Gomes), umbu (Spondias tuberosa Arruda), pequi (Caryocar coriaceum Wittem.) e cambuí (Myrciaria tenella (DC.) O. BERG).

Estudos têm enfatizado a utilização de PFNM com enfoque nos aspectos econômicos, sociais e ambientais (LINHARES e PINHEIRO, 2013; GAMA et al., 2017; OLIVEIRA et al., 2017). Porém, é escassa a informação sistematizada sobre espécies potenciais, dados de produção, preço de revenda, processos de produção (manejo e conservação), industrialização e comercialização destes produtos (FILDLER et al., 2008). Assim, é indispensável o diagnóstico dessas espécies, seus usos e benefícios, visando o melhor proveito dos produtos e subprodutos da biodiversidade pelas populações locais (GAMA et al., 2017).

O extrativismo, em diversas formações vegetais, é uma atividade que se realiza sempre de forma integrada à agricultura familiar e constitui-se um meio determinante para a sua sobrevivência e reprodução sociocultural (OLIVEIRA e VELASCO, 2018). Os produtos do extrativismo florestal desempenham uma ação fundamental em processos culturais mais específicos, como a construção de identidades/territorialidades, fortalecimento da memória social, alimentação e práticas espirituais, portanto, integram o patrimônio histórico e cultural brasileiro (MMA, 2018).

A mangabeira (Hancornia speciosa Gomes - Apocynaceae) é uma frutífera nativa do Brasil, com ampla distribuição geográfica, ocorrendo desde as regiões Centro-Oeste, Sudeste e Norte dos Cerrados, até os Tabuleiros Costeiros e Baixadas Litorâneas do Nordeste (VIEIRA et al., 2017). Possui grande importância socioeconômica, cultural, nutricional, ornamental, medicinal e ecológica. Seu fruto é uma importante fonte de renda da agricultura familiar no Nordeste, principalmente quando são processados em doces, sucos, polpas, geleias e outros derivados. Todavia, por ocorrer em áreas de grande impacto dos desmatamentos, devido à intensa especulação imobiliária, implantação de monoculturas, do turismo e extrativismo exploratório, intensificou-se a vulnerabilidade das populações de mangabeiras em diversas regiões do Nordeste, colocando em risco a existência da espécie (OLIVEIRA, 2016).

No Nordeste, o extrativismo dessa planta é significativo, sendo essa atividade responsável pelo sustento de muitas famílias e pelo potencial econômico para a região. Por ser uma espécie que ainda não foi domesticada, a maior parte da colheita dos frutos advém do extrativismo de plantas remanescentes, pois torna-se economicamente mais viável extrair os recursos que se encontram dispostos naturalmente, que cultivá-los (OLIVEIRA e ALOUFA, 2019). Nesse aspecto, considerando-se as características e potencialidades de cada região, o manejo de PFNM constitui um importante meio para alcançar o desenvolvimento com bases sustentáveis (MACHADO, 2008). Isso ocorre porque se parte do princípio de que a exploração desses recursos é menos impactante em termos ecológicos e por ser uma fonte de renda e desenvolvimento local (FACHINELLO, 2010). Todavia, no Brasil, não existe normatização que regulamente o seu manejo, o que pode estar contribuindo para intensificar os conflitos socioambientais em decorrência do extrativismo (JESUS e GOMES, 2012).

A maior produção dos frutos ocorre em estados do Nordeste brasileiro (1657 t), com destaque para o estado da Paraíba que, atualmente, é o maior produtor nacional, com 733 t (44,24\%), seguido por Sergipe (22,51\%), Bahia (14,66\%) e Rio Grande do Norte (9,17\%) (IBGE, 2018). Embora se destaque pelo seu potencial socioeconômico e ambiental, ressalta-se que, nos últimos 10 anos, houve uma tendência à redução dos frutos, afetando diretamente a cadeia produtiva da mangaba. Apesar do grande potencial 
dessa frutífera para a região Nordeste, a atual produção não é suficiente para atender à demanda do mercado consumidor, já que a produção dessa cultura é basicamente extrativista. Estudos que analisem o conhecimento sobre o potencial, usos e impactos econômicos do extrativismo da mangaba para as populações locais se tornam essenciais, podendo contribuir com informações estratégicas para subsidiar a sua conservação.

Diante do exposto, este estudo objetivou caracterizar o extrativismo da mangaba e avaliar o seu potencial de geração de renda no município de Nísia Floresta-RN, visando contribuir com a elaboração de políticas públicas que subsidiem a conservação da espécie.

\section{Material e Métodos}

\section{Área de estudo}

A pesquisa foi realizada nas comunidades rurais de Timbó, Boa Água e Bonfim, município de Nísia Floresta- RN, distantes $4,9 \mathrm{Km}, 7,9 \mathrm{Km}$ e 3,8 $\mathrm{Km}$ da cidade sede, respectivamente (Figura 1), no período de agosto de 2017 a setembro de 2018. O município de Nísia Floresta está situado no litoral do Estado do Rio Grande do Norte, na microrregião Macaíba, pertence à Região Metropolitana de Natal-RN e ocupa uma área de $307,842 \mathrm{~km}^{2}$ (IDEMA, 2013).
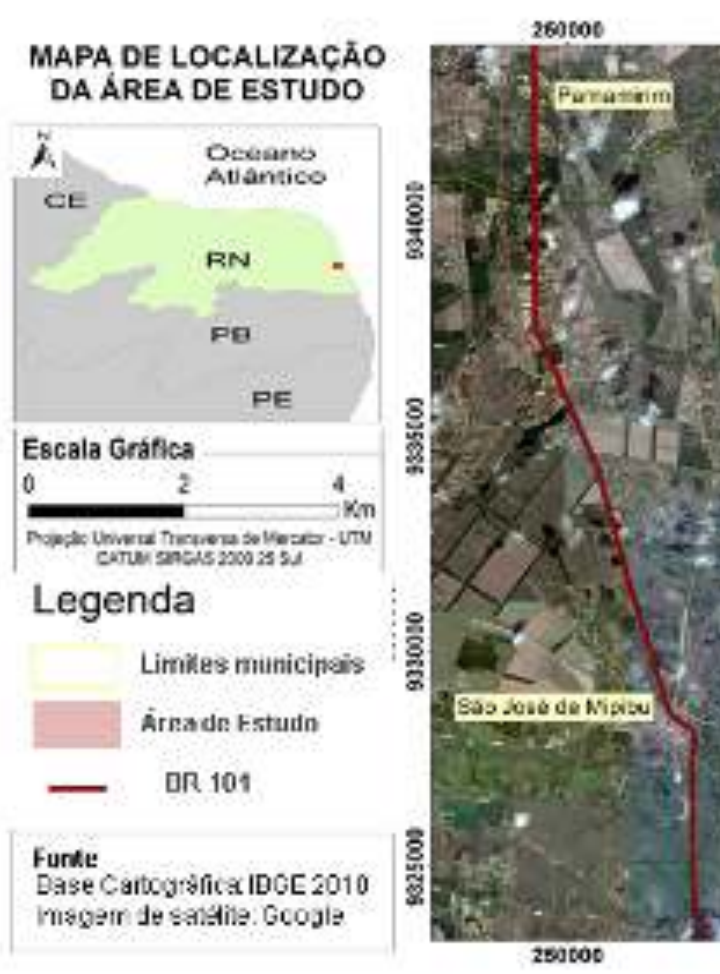

$26560 \mathrm{~s}$

260600

26650 s

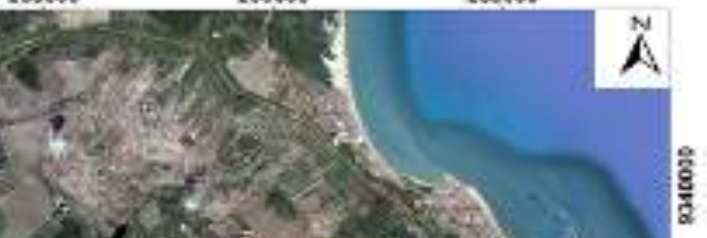

Figura 1. Localização das comunidades de Timbó, Bonfim e Boa Água, em Nísia Floresta- RN.

A vegetação da localidade, assim como do seu entorno, é constituída pela maior remanescente de Mata Atlântica do Rio Grande do Norte, formada por vegetação de restinga, mangue, várzeas, Tabuleiros Costeiros e por Floresta Subperenifólia (IDEMA, 2013). Parte dessa área de Mata Atlântica é conhecida como Floresta Nacional - FLONA de Nísia Floresta, com área de 175 hectares (IDEMA, 2013). Ressalta-se que a vegetação de restinga é protegida por lei, segundo o Novo Código Florestal Brasileiro, como área de preservação permanente (BRASIL, 2012). 
Para o levantamento de dados, foram realizadas entrevistas semiestruturadas com público heterogêneo, em relação a sexo e idade. A escolha deste instrumento de pesquisa pode ser justificada pelo fato de assegurar maior liberdade de expressão do entrevistador e entrevistados, permitindo, assim, captar elementos que possam surgir na entrevista (ALBUQUERQUE et al., 2010). Utilizou-se, também, a observação participante, que consiste na participação real do conhecimento de vida da comunidade, do grupo ou de uma determinada situação (GIL, 2008).

A escolha das três comunidades levou em consideração a quantidade de atores envolvidos e a acessibilidade ao local. Os informantes da pesquisa foram escolhidos através da técnica de "bola de neve" (ALBUQUERQUE et al., 2010), totalizando 59 participantes, sendo 28 em Timbó, 10 em Boa Água e 21 em Bonfim. Para justificar o tamanho da amostra, utilizou-se a técnica de saturação teórica dos dados, que é usada para determinar ou fechar o tamanho final de uma amostra em estudo, descontinuando a obtenção de novos componentes, quando as respostas, na opinião do pesquisador, começam a se repetir ou apresentam certa redundância (FONTANELLA et al., 2008).

A pesquisa foi aprovada pelo Comitê de Ética em Pesquisa da Universidade Federal do Rio Grande do Norte, sob o registro CAAE de no 80013917.9.0000.5537. Utilizou-se o Termo de Consentimento Livre e Esclarecido (TCLE), quando os participantes, após serem informados sobre o desígnio e natureza da pesquisa, foram convidados a participar do estudo.

O roteiro das entrevistas semiestruturadas incluiu perguntas sobre o perfil socioeconômico (gênero, idade, escolaridade, número de pessoas que compõem o grupo familiar, ocupação e experiência/tempo de coleta), produção, formas de comercialização, valor praticado, tecnologias sociais empregadas e conhecimentos etnobotânicos associados ao extrativismo da mangaba. Para o processamento dos dados utilizou-se planilhas adequadas, com vistas a uma estatística descritiva.

\section{Resultados e Discussão}

\section{Caracterização socioeconômica dos informantes}

Do total de 59 informantes, $47,46 \%$ são do gênero masculino e $52,54 \%$ do gênero feminino. Quanto à idade, verificou-se que $40,68 \%$ dos entrevistados estão na faixa etária entre 41 a 60 anos, $28,81 \%$ corresponde à faixa acima de 60 anos, 20,34\% na faixa de 31 a 40 anos, e $10,17 \%$ possuem de 20 a 30 anos. Os participantes possuíam baixa escolaridade, $59,32 \%$ deles não tinham o ensino fundamental completo, apenas $8,47 \%$ concluiu o ensino médio e $22,03 \%$ são analfabetos. 0 número de pessoas por família variou entre um e nove, sendo que a maioria (42,37\%) é composta por 3 a 4 pessoas.

Como em outros produtos do extrativismo, a exemplo da mangaba (SANTOS e SOUZA, 2016), dos cocos babaçus (SHIRAISHI NETO, 2017) e do cambuí (GAMA et al., 2017), verificou-se a predominância da mulher na coleta, comercialização dos frutos e propagação das plantas. Isso sugere que, mesmo tendo aumentado a participação dos homens e até das crianças nos últimos anos, com a valorização econômica da atividade, as mulheres têm concentrado socialmente suas tarefas no extrativismo, o qual tem atribuído a elas uma maior participação na constituição do patrimônio e da renda.

Com relação às fontes de subsistência, o extrativismo da mangaba, o turismo e a pecuária são as principais delas, seguidos pela agricultura e comércio. A maioria dos informantes utiliza a extração da mangaba como fonte complementar de renda, porém, para alguns deles, essa atividade é considerada a única fonte de renda. Por tratar-se de uma atividade sazonal, a combinação de diferentes atividades é uma forma de suprir as demandas, sendo comum nas três comunidades a alternância com outros serviços (pesca, artesanato, agricultura, turismo, serviços ocasionais de pedreiro e servente). Assim, diversos autores têm substituído o termo "extrativista" por "agroextrativista", indicando um possível reconhecimento de que o extrativismo é uma prática integrada a outras atividades agrícolas e não agrícolas (SILVA e MIGUEL, 2014).

De modo geral, todas as atividades produtivas desenvolvidas nas comunidades de Timbó, Boa Água e Bonfim, dentre elas a extração da mangaba, não garantem fonte regular de recursos. Para alguns, a única renda permanente é a aposentadoria. A venda da mangaba é um grande subsídio na renda familiar, porém, como a atividade é sazonal, é necessário que os integrantes das famílias recorram a 
outras fontes remunerativas e dependam de auxílio governamental, como o Programa Bolsa Família. Em estudos com a caracterização do extrativismo do látex de janaúba (Apocynaceae), Linhares e Pinheiro (2013) verificaram que a aposentadoria é a fonte permanente de recursos, que garante o provimento de bens essenciais para os moradores dos povoados de Alcântara nos períodos em que a agricultura, a pesca e o extrativismo atravessam dificuldades.

Quanto à experiência (tempo de coleta), a maioria atua de 1 a 10 anos (30,31\%) e 11 a 20 anos $(30,31 \%)$, seguida de 31 a 40 anos $(25,42 \%)$, com predomínio de catadores na faixa etária de 41 a 60 anos. O restante atua entre 21 a 30 anos (6,78\%) e 41 a 50 anos (6,78\%). O período máximo da atividade no local foi de 50 anos. Os resultados apontam que a coleta da mangaba é realizada por diferentes gerações e o conhecimento sobre a atividade está bem difundido nas três comunidades.

O público heterogêneo em relação a sexo e idade sugere que, além de ser uma prática cultural, continua a auxiliar o homem no campo, em razão, também, da falta de empregos no mercado formal. Vale ressaltar que os catadores mais antigos têm deixado a atividade, em virtude do turismo que vem crescendo na região, devido à presença das lagoas de Carcará, Boa Água e Bonfim, onde atuam, sobretudo, em bares e como vendedores ambulantes (OLIVEIRA e ALOUFA, 2019). Silva et al. (2017) verificaram que o acesso às novas oportunidades ou mesmo por uma questão de melhoria econômica das famílias, estão contribuindo para distanciar as novas gerações dos usos tradicionais do babaçu.

Diante disso, torna-se essencial o envolvimento das comunidades tradicionais, assentados rurais e comunidades rurais em geral, no agroextrativismo, pois esse pode fornecer alimentos para o autoconsumo, excedente para comercialização, artesanato, entre outras possibilidades que permita a geração de renda e garanta a permanência da população rural no campo, evitando o êxodo para grandes centros urbanos, inchados e carentes de estrutura (DUTRA e SOUZA, 2017).

\section{Conhecimentos etnobotânicos}

Com relação às partes usadas (fruto, folha, raiz, caule e látex), os informantes atribuíram diversos usos, sendo o fruto quem mais se destacou ( $100 \%$ das citações), com usos na alimentação humana através do consumo in natura ou processado (polpa, sorvete, mousse, dindin, picolé, geleia, doce, licor, entre outros); látex $(15,25 \%)$ com uso na produção de borracha e medicinal; a casca $(6,78 \%)$ para uso medicinal e folha $(5,08 \%)$ para adubo (Tabela 1). Conforme os dados obtidos, o principal tipo de uso da mangaba é o alimentício, além disso, 52,54\% dos entrevistados citaram o uso da mangaba para fins medicinais, 5,08\% para fins madeireiros e 3,39\% para fins laticíferos.

Tabela 1. Usos relacionados ao extrativismo da mangaba, segundo relatos dos catadores no município de Nísia Floresta- RN.

\section{Conhecimentos etnobotânicos}

Tipos de usos

Formas de usos

Práticas de manejo

Existência de variação fenotípica dos frutos

Tecnologia social

Medidas mitigadoras de impacto

Locais de ocorrência

Aspectos dos frutos em relação às suas áreas de ocorrência

Porte da planta preferível
Alimentício, medicinal, laticífero, madeireiro e adubo.

Suco, polpa, sorvete, mousse, dindin, picolé, licor, geleia, doce, consumo in natura, fins medicinais (hérnia, gastrite, diabetes, úlcera, pressão alta, cicatrização e anemia), lenha/carvão, borracha e adubo.

Em granjas e quintais são comuns as práticas de limpar, podar, adubar e eliminação de plantas epífitas; nos tabuleiros: eliminação de plantas epífitas.

Mangaba de "sombra" os frutos são maiores, mais doces e mais saborosos, de cor verde tendendo a amarelo e casca fina. Já as mangabas de "sol" ficam amarelas, com manchas vermelhas e casca grossa.

Utilização de vara com gancho para evitar danos à planta durante a coleta dos frutos.

Evitar quebrar galhos, subir nas mangabeiras e tirar frutos verdes.

Áreas de tabuleiro, restinga e granjas.

Áreas de tabuleiro produzem frutos menores, mais avermelhados e a casca é grossa; áreas de granjas produzem frutos maiores, mais doces, de melhor qualidade e a casca é fina.

Mangabeiras de porte baixo, por facilitar a coleta dos frutos. 
Os usos associados à espécie estão relacionados, principalmente, com a alimentação humana, através do consumo do fruto in natura ou após beneficiamento (geleias, polpas, doces, bolos, licores), ambas as opções com boa aceitação no mercado (OLIVEIRA et al., 2017). Porém, outros usos menos evidentes podem ser empregados, tal qual o combustível, visto que a madeira pode ser utilizada como lenha de uso doméstico, bem como o uso medicinal da casca, folhas e raízes (LIMA e SCARIOT, 2010). Por exemplo, a casca produz diversos tipos de flavonoides, antocianinas, catequinas e taninos (MORAES et al., 2008). As folhas são usadas para extração de fármacos no controle da pressão arterial (SILVA et al., 2011). Na medicina popular, o látex de mangabeira é utilizado para promover funções hepáticas e tratar doenças dermatológicas, diabetes e hipertensão (RITTER et al., 2002). Lima et al. (2012), em estudos sobre a diversidade e usos de plantas do cerrado, verificaram que as frutíferas mais citadas foram mangaba $(H$. speciosa), pequi (C. brasiliense) e bacupari (Tontelea micranta). Dentre os usos atribuídos a essas frutíferas, foram reconhecidos de dois a oito, porém, o mais comum foi para a alimentação humana.

De acordo com a percepção local, há duas safras na região, denominadas safra de inverno e safra de verão (Figura $2 \mathrm{~A}-\mathrm{B}$ ). Essa última, correspondente à produção entre os meses de janeiro a abril, é a que gera maior lucro. A de inverno ocorre entre julho a outubro, porém, as mangabas apresentam menor qualidade. Isso pode ser observado nos discursos seguintes: "No inverno os frutos são menores e dá bastante, mas adoece muito por causa da chuva [...] ela não gosta de muita chuva não." (C.1, 65 anos). "As do verão são melhores. As de inverno a gente usa, mas não é muito boa não." (C.28, 59 anos). A estimativa da colheita varia conforme a estação do ano e, geralmente, no inverno, a produção é menor e rápida, pois decorre da intensificação das chuvas nesse período, impedindo a maturação completa dos frutos. No verão, a produção é gradativa e elevada, obedecendo à sazonalidade da fruta, que é peculiar de clima quente (SANTOS, 2007).

Quando questionados sobre a existência de variação fenotípica entre os frutos de $H$. speciosa, verificou-se que a maioria dos informantes diferenciam os frutos da mangaba pelos seguintes nomes locais: mangaba de "rama", mangaba de "pau", mangaba de "sol" e de "sombra". As mangabas de "sombra" e de "sol" variam na cor e as de "rama" e "pau" variam no tamanho (Figura 2). Como relatado nos discursos seguintes:

"Tem as mangabas de sombra e as de sol. As mangabas de pau são as grandes que coloca no gancho do pau. As da sombra que ficam embaixo da sombra não ficam vermelhas não, ficam brancas, e quando amadurece fica branquinha (a polpa); e as de sol ficam com manchas vermelhas [...] As de pau crescem mais e as de rama são menores. As de pau colocam no começo da safra que é mês de novembro-dezembro e as miúdas são as de rama." (C. 42, 52 anos).

"Tem uma mangaba que bota embaixo das folhas (mangaba de sombra) aí ela fica bem esverdeada, a gente pensa que ela tá verde, só que elas já tão no ponto; as de sol são aquelas pintadinhas (amarela com manchas vermelhas), avermelhadas; as de pau coloca mais no tronco, entre um galho e outro. E as de rama ficam mais nas pontas" (C.37, 50 anos). 


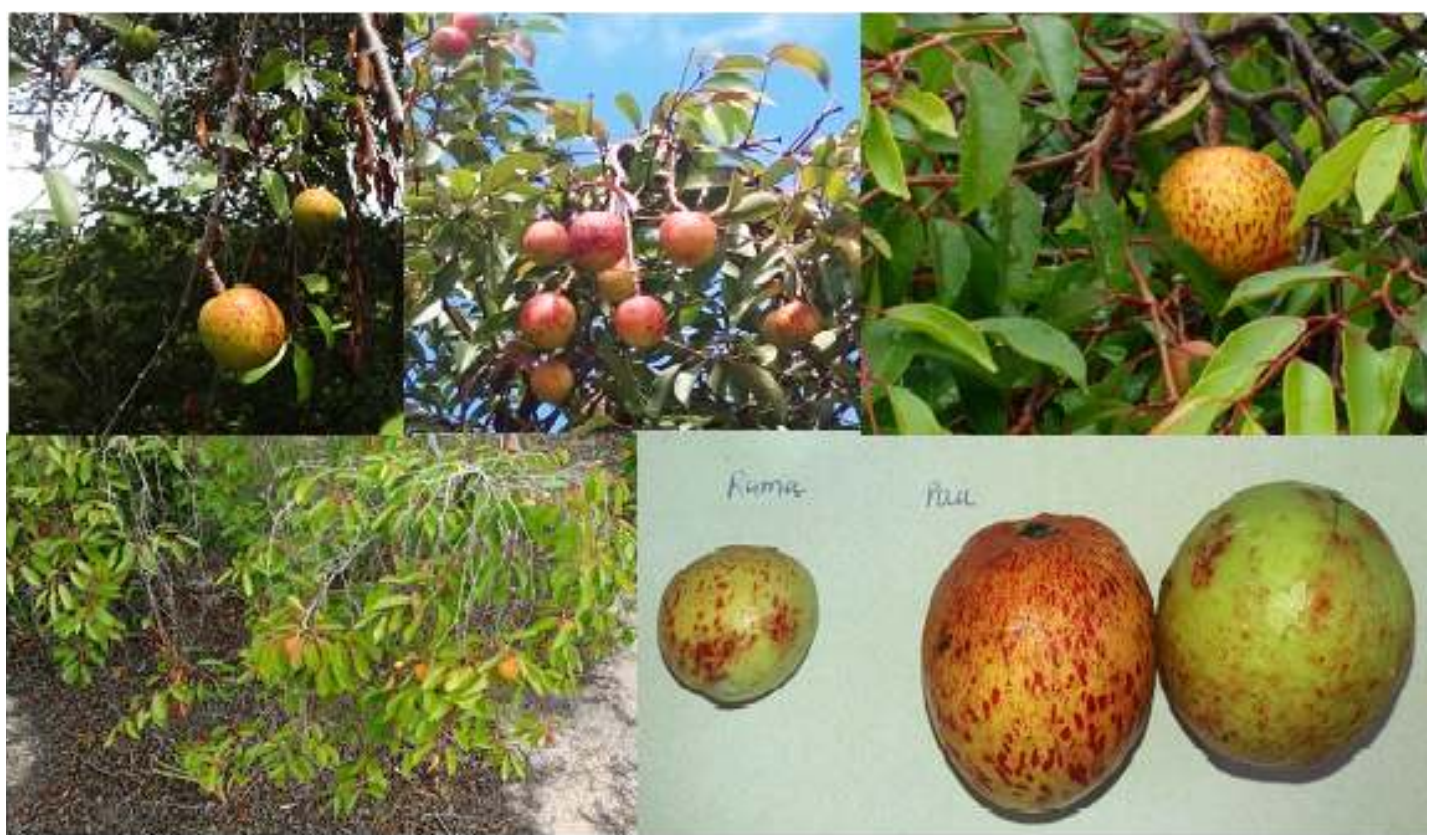

Figura 2. Frutificação de safra de verão (A) e inverno (B), mangaba de "pau" (C) e de "rama" (D).

Nas localidades estudadas, a maioria dos informantes conhece as potencialidades de uso da espécie, evidenciando o seu valor cultural para as populações extrativistas. Além disso, demonstraram conhecer diversos locais de coleta e estabeleceram relações entre esses locais e variações fenotípicas dos frutos (tamanho, coloração, sabor), que são dados importantes para estudos acerca dos diversos tipos de mangaba existentes na região. Com relação aos locais de coleta, a maioria dos entrevistados realiza o extrativismo em tabuleiros "livres" ou em áreas de terceiros, poucos possuem mangaba em terras próprias.

Para Brito e Mota (2010), as catadoras de mangaba são detentoras de amplo conhecimento sobre as áreas extrativistas, sendo capazes de identificar peculiaridades do ecossistema, como a vegetação (desenvolvimento e fenologia), tipos de solo, animais, entre outros. Portanto, o conhecimento sobre os aspectos morfológicos, fenológicos, dispersores naturais e solo são essenciais para a propagação, manejo e conservação da espécie. O estudo e a análise desse conhecimento, o valor cultural, as formas de manejo e usos tradicionais dos componentes da flora são subsídios importantes para promover o desenvolvimento sustentável em populações tradicionais (GAMA et al., 2017).

\section{Caracterização da coleta, cadeia produtiva e comercialização da mangaba}

Quando questionados sobre espécies comerciais nativas da região conhecidas ou que fazem uso, a maioria só comercializa a mangaba. Das outras espécies citadas, a exemplo do cambuí (Myrcia sp.), guabiraba (Campomanesia synchoma Berg.), murta (Myrtus communis), ubaia (Eugenia uvalha), maçaranduba (Manilkara spp), guajiru (Chrysobalanus icaco L.), cajarana da mata atlântica (Cabralea cangerana), entre outras, quando utilizadas, geralmente, é para o consumo próprio. Tal dado demonstra que a mangaba tem um papel significativo na geração de renda para as famílias da região.

Segundo os informantes, a coleta da mangaba é mais intensa no período de janeiro a abril (safra de verão) e, normalmente, é iniciada às $3 \mathrm{~h}$ ou $4 \mathrm{~h}$ da madrugada, e retornam ao final do dia, sobretudo quando os tabuleiros percorridos são distantes. A atividade é realizada em grupos de pessoas da mesma família ou da comunidade. A coleta é efetivada em áreas de tabuleiros (próximos e/ou distantes), em quintal e em propriedades privadas. 0 meio de transporte dos frutos, do local da coleta até o armazenamento, geralmente é através da bicicleta, carroça, a pé ou veículo automotor. Alguns usam a motocicleta quando os tabuleiros são distantes e o acesso é limitado, por causa da mata fechada e das estradas que são estreitas. Ressalta-se que o transporte depende das condições financeiras do coletor de mangaba e da distância percorrida. 
A coleta é feita, comumente, com o auxílio de um gancho de arame acoplado a uma vara (Fig. 3A) com os frutos ainda na árvore. Outros coletam apenas as caídas da planta, para não "machucar" as mangabeiras. Verificou-se que o sistema extrativista dominante nas três comunidades inclui métodos e tecnologia simples, desenvolvidas através de conhecimentos locais e que são propagados ao longo de gerações.

Constatou-se que, embora a quebra de galhos e a técnica de passar o fogo rápido sejam práticas comuns na região para aumentar a produção dos frutos, a maioria é contra o uso de tais práticas, por prejudicarem as mangabeiras e, consequentemente, a produção do ano seguinte. Mota e Santos (2008), verificaram que as catadoras de mangaba de Barra de Coqueiros/SE evitam coletar as mangabas verdes, quebrar galhos e cortar as árvores, mostrando preocupação com a conservação da espécie. Logo, reconhecem que a atividade constitui uma importante fonte de renda e de reconhecimento social. Não se pode esquecer que o manejo e conservação adequados da mangaba são elementos essenciais para a existência da espécie. Portanto, as boas práticas de manejo e conservação da espécie são indícios de que as comunidades desempenham importante papel como comunidades sociobiodiversas e envolvidas com as práticas agroecológicas.

Dentre as práticas de manejo da mangabeira, Lima e Scariot (2010) destacam: evitar coletar todos os frutos da árvore para não afetar a reprodução da espécie; evitar derrubar as flores para não comprometer a produção de frutos; não coletar a mangaba verde; coletar os frutos "de vez"; realizar as coletas durante toda a safra, visto que o processo de maturação é desuniforme ao longo do período de produção (safra).

Para a comercialização, na maioria das vezes são coletados os frutos que estão semimaduros ou "de vez" (fruto ligeiramente amarelado e textura tenra), para evitar perdas, pois os frutos maduros apresentam alta perecibilidade e são sensíveis ao transporte (Fig. 3B). Após a coleta e transporte dos frutos, estes são lavados para a remoção de resíduos do látex, postos para secar e, depois, enfurnados. $\mathrm{O}$ armazenamento é feito em caixas plásticas até o amadurecimento (Fig. 3C). Quando há compradores, os frutos são embalados em sacos plásticos e quando não, são conservados em geladeira ou freezer. Os entrevistados também relataram que há perda de frutos por falta de compradores ou local para conservar, pois a maioria não dispõe de freezer e até mesmo de geladeira. Devido à comercialização ser basicamente dos frutos in natura, isso acaba limitando a valorização do produto, já que outras formas de processamento de derivados da mangaba não são utilizadas pelas comunidades.

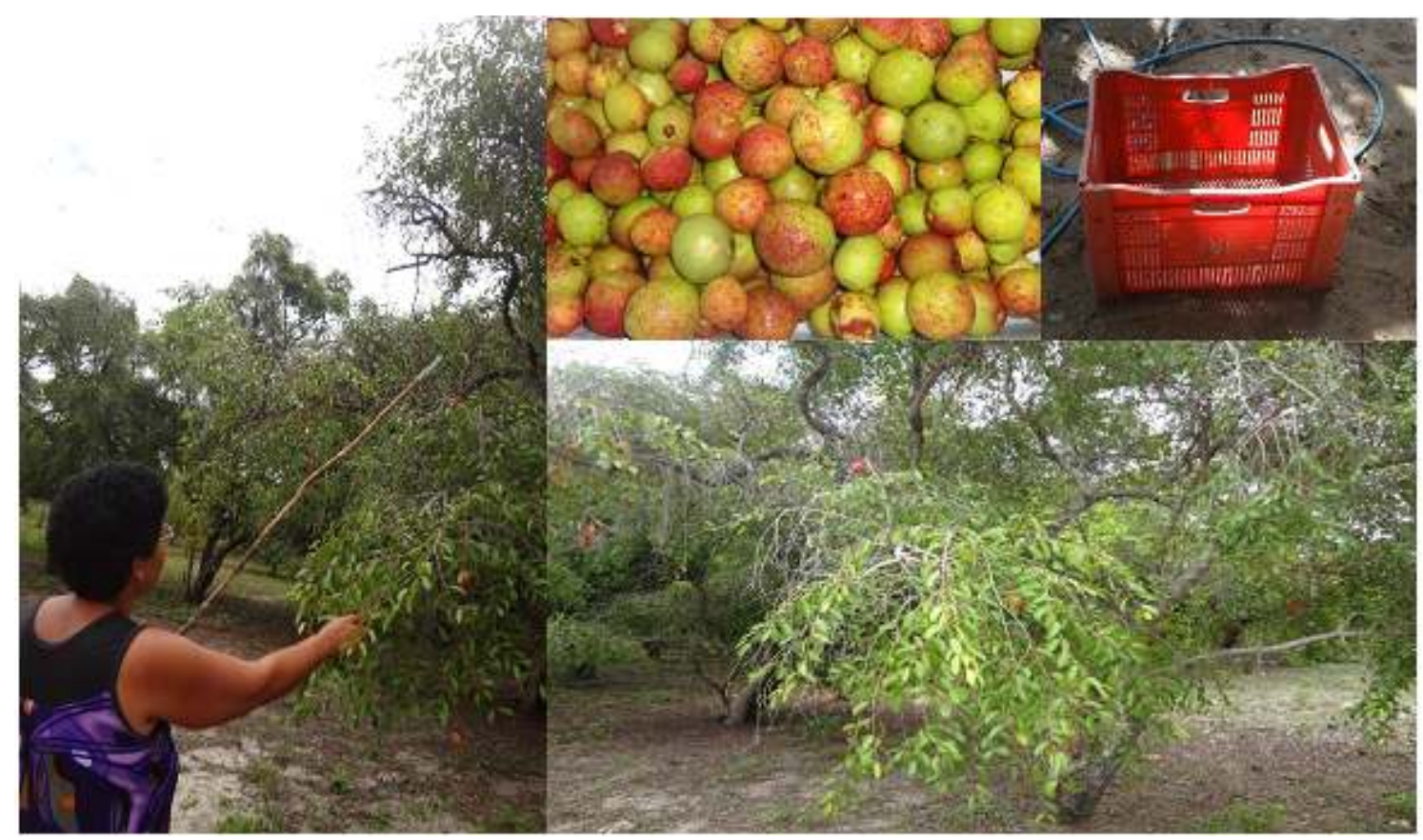


Figura 3. Tecnologia social utilizada para coleta da mangaba (A); frutos semimaduros (B); caixa de pesagem e venda das mangabas (C); indivíduo de mangabeira (D). Fonte: Arquivo pessoal, 2019.

Conforme a maioria dos extrativistas, os indivíduos de mangabeira estão reduzindo nas áreas de ocorrência (72,88\%). Com relação às causas dessa redução, a maioria atribuiu aos desmatamentos para monoculturas de cana-de-açúcar e coqueiros, ao aumento das áreas privadas, inclusive com corte das mangabeiras para impedir a entrada dos coletores nas propriedades, às queimadas e à construção de casas. Como se pode observar nos discursos dos entrevistados: "Diminuiu porque teve uma área que foi desmatada todinha pra fazer um sítio de coco." (C42, 52 anos); "Diminuiu, porque foi o desmatamento, a habitação (construção de casas), aqui tinha mais do que tem hoje, nesse terreno mesmo, então diminuiu. O pessoal foi habitando, construindo e arrancando os pés de mangaba." (C46, 69 anos).

De acordo com a percepção local sobre a produção de frutos no começo da prática extrativista e sua quantidade atualmente, a maioria $(64,41 \%)$ afirma que houve redução das mangabas, enquanto $25,42 \%$ afirmam que aumentou e $18,64 \%$ não observaram mudança. Os impactos ambientais percebidos pelos informantes locais, que acarreta a diminuição dos frutos, incluem o desmatamento, aumento das áreas privadas, restringindo a entrada dos coletores, a quebra de galhos, além das práticas irregulares de queimadas. Entretanto, para alguns entrevistados a diminuição dos frutos está relacionada com os fatores ambientais, dentre eles, a seca, o excesso de chuva e a diminuição de insetos polinizadores. A percepção local pode ser verificada em alguns discursos: "Diminuiu porque vai tirando as mangabeiras de dentro das matas aí as mangabas vão diminuindo." (C8, 37 anos); "Diminuiu muito, acho que é a dificuldade, tudo tá difícil, é a dificuldade de chuvas, clima, tempo." (C5, 38 anos).

Resultados semelhantes foram observados por Oliveira et al. (2017), em estudos com os catadores de mangaba de Sergipe. Conforme os autores, a redução da quantidade de frutos está relacionada aos seguintes fatores: a quantidade de chuvas, ou seja, pouca chuva limita a quantidade de água para produção dos frutos. Em contrapartida, o seu excesso pode provocar a queda das flores quando ainda estão nas árvores ou dos frutos que estão jovens, devido à força da água; desmatamentos e queimadas; e aumento de "catadores ocasionais" nos últimos anos, motivados, provavelmente, pelo fato de a venda da mangaba gerar subsídios financeiros para as famílias.

Vale salientar que os desmatamentos apontados como o principal problema local para a redução das mangabeiras têm seu cenário agravado em virtude das comunidades se situarem em áreas que o turismo vem despontando, assim, acentuando o interesse por áreas privadas e granjas na região (OLIVEIRA, 2016). Saraiva et al. (2012) destacam que esse impacto se apresenta com maior intensidade nas terras do litoral, onde a expansão imobiliária denota força econômica e se torna detentora destas áreas antes visitadas pelos coletores. Logo, a necessidade de conservar a espécie não se limita apenas ao impacto econômico para as famílias envolvidas e inclui, ainda, a conservação da biodiversidade local, a manutenção dos serviços ecológicos, das cadeias alimentares (fauna e flora) e das relações intra e interespecíficas da fauna (PRIMACK e RODRIGUES, 2006).

As principais dificuldades na coleta da mangaba relatadas pelos informantes são o transporte (carregar peso), distância (caminhar longas distâncias até os tabuleiros), acesso aos locais de coleta, os perigos existentes nos locais de coleta (insetos, cobras), e a própria coleta, conforme observadas nos discursos seguintes: "O transporte, porque nem todo mundo tem. Aí tem que carregar na cabeça e os locais de coleta são distantes." (C.3, 67 anos). "É porque muitos cercam e não deixam a gente tirar, se apossam das terras." (C.48, 63 anos). "[...] pra ir buscar, é longe, as estradas são esburacadas, as áreas estão cercadas, tem muita cobra, maribondo, lagarta." (C.9, 54 anos). "[...] onde tem maribondo, aquele maribondo caboclo, eu não gosto de tirar não porque dizem que ele protege as mangabeiras." (C.11, 58 anos). Essa percepção da presença de insetos, relacionada à proteção natural das mangabeiras, mostra uma rede de interações das comunidades com as práticas simbólicas, representando seus saberes ecológicos. Elas constroem, em grande parte, suas crenças e sabedorias na relação direta com a natureza (SOUSA, 2017). São indivíduos que nasceram e desenvolveram suas práticas laborais e o modo como compreendem o meio que os circunda (contexto) a partir do convívio direto com a natureza (TOLEDO e BARRERA-BASSOLS, 2015). 
Tais dificuldades identificadas na coleta envolvem uma série de fatores, dentre eles: o acesso aos recursos, que estão cada vez mais limitados, devido à privatização das áreas, e o acesso restrito aos tabuleiros que, antes, eram livres. Logo, eles têm que recorrer a tabuleiros cada vez mais distantes, e isso implica distância e transporte, pois muitos não dispõem de recursos ou meios para se deslocar, tendo que ir a pé. Além das limitações que geram custos na coleta, também ocorre a desvalorização do preço dos frutos quando são comercializados aos atravessadores. Como a maioria não tem como armazenar a produção ou investir em outras formas de beneficiamento, vendem pelo valor ofertado. Apesar disso, a atividade ainda é a principal forma de complementação de renda para a maioria das famílias na região. Dentre as fraquezas e ameaças identificadas no extrativismo da mangaba em Sergipe, Oliveira et al. (2017) consideraram três pontos críticos prioritários: poucos compradores para produtos beneficiados; não dispor de terras próprias para realizar o extrativismo; queimadas e desmatamentos.

No que se refere à cadeia produtiva da mangaba, a maioria dos entrevistados (83,05\%) comercializa sua produção para os atravessadores, que por sua vez vendem para a fábrica de polpas do município de Parnamirim/RN e compradores de outros estados, a exemplo de Paraíba-PB e Recife-PE. Os $16,95 \%$ restantes vendem para lanchonetes, feiras livres, mercado público ou utilizam para consumo próprio. As dificuldades relatadas pela maioria dos coletores vão desde a própria coleta até à comercialização da mangaba. O município não dispõe de uma cooperativa para facilitar os trabalhos de beneficiamento e processamento dos frutos, logo, a falta de incentivos e investimentos resulta na desvalorização dessa cultura e dificulta o seu reconhecimento (OLIVEIRA e ALOUFA, 2019). Portanto, torna-se evidente a necessidade de se implementar políticas públicas voltadas a atender às necessidades dessas comunidades extrativistas.

Dias et al. (2014), ao contrastarem a cadeia produtiva de frutíferas nativas de restinga: mangaba (H. speciosa); pitanga (Eugenia uniflora L.); caju (Anacardium occidentale L.) e aroeira (Schinus terebinthifolius Raddi), observaram que, com exceção desta última, os outros frutos são comercializados em uma curta cadeia produtiva local. Para os autores, isso é decorrente do pouco conhecimento sobre o beneficiamento e à falta de subsídios locais que impulsionem a utilização e comercialização, além da instabilidade do setor local, que privilegia produtos externos à região ao invés da produção local.

Com relação à desvalorização da cadeia produtiva da mangaba, os entraves na comercialização dos frutos aumentam a dependência dos agricultores em relação aos atravessadores, por não possuírem meios viáveis para transportar os produtos da zona rural aos municípios onde estes poderiam ser comercializados (ANDRADE et al., 2014). Além disso, ocorre a depreciação quando os frutos são repassados aos atravessadores, o que, geralmente, inviabiliza a produção e desmotiva os coletores a obterem renda através do extrativismo (OLIVEIRA e ALOUFA, 2019). Em Barra dos Coqueiros/SE, Santos (2007) verificou que os frutos de mangaba são vendidos diretamente aos feirantes e outros compradores (consumidores, donos de lanchonete, processadores); somente $3 \%$ vendem seus produtos às fábricas de polpas. Conforme a autora, apesar da estratégia de venda a diversos compradores ser recorrente e lucrativa a maioria das catadoras reconhece que é a mais arriscada, pois podem não vender tudo e perder o produto.

O quilo da mangaba é vendido em faixa de preço de $R \$ 1,50$ a 3,00, variando de $R \$ 1,00$ a 10,00 fora da safra. Conforme os informantes locais, na safra, os preços geralmente caem, sendo comercializado por $\mathrm{R} \$ 2,00$ a 2,50. A maior parte dos frutos é comercializada, para a fábrica, a 2,00-2,50 R\$/Kg, independentemente de estar na safra ou não. Os preços variam entre os catadores, conforme é observado nos discursos seguintes: "No começo da safra é 1,50 e no final da safra é 1,20. Fora da safra diminui, até porque a gente não tem opção e tem que vender." (C8, 37 anos); "No ano passado, eles estavam vendendo a 2,00 e, no final, de 1,50. Fora da safra é a mesma coisa, não aumenta nem baixa, fica de 1,50." (C39, 50 anos). Ressalta-se que, para a unidade litro, geralmente utilizada nas feiras livres pelos catadores de mangaba, eles utilizam como medida padrão a lata de óleo comestível, com capacidade para $900 \mathrm{~mL}$. Todavia, também são comercializados por caixa, com capacidade para 30 a $35 \mathrm{Kg}$, e o preço varia de R\$ 30 a 45,00 por caixa.

Verificou-se, ainda, a variação dos preços conforme a safra e as exigências dos compradores. Porém, muitos relataram que, durante a entressafra, período de escassez dos frutos, os preços diminuem. Santos e Souza (2016) verificaram que, durante a entressafra, os preços da mangaba em Sergipe são mais 
altos, por causa da baixa produtividade. Conforme os autores, no período de safra, o valor da caixa com $27 \mathrm{~kg}$ chega a custar entre $R \$ 15,00$ e $R \$ 20,00$, e o litro entre $R \$ 1,00$ e $R \$ 3,00$, enquanto na entressafra os preços da caixa variam entre $R \$ 50,00$ e $R \$ 60,00$, e o litro entre $R \$ 5,00$ e $R \$ 6,00$. Vale salientar que, como a coleta é mais intensa no período de safra, e nos outros períodos são desenvolvidas atividades paralelas, pode-se inferir que, de fato, essa diversificação de atividades contribui para o sustento dos coletores da região (OLIVEIRA e ALOUFA, 2019).

Segundo Alves (2010), três características naturais marcantes dentro dos PFNM alimentícios podem ser observadas: a sazonalidade em relação à produção, a perecibilidade dos mesmos e a variação de produção, tanto dentro de uma mesma espécie vegetal quanto de um ano para o outro. Nesse aspecto, torna-se extremamente difícil fazer generalizações em relação aos mesmos.

A renda média familiar obtida com o extrativismo da mangaba é estimada em $\mathrm{R} \$ 3.314,08 /$ anual, correspondendo a $30 \%$ da renda anual da família. Porém, o rendimento obtido por família varia de acordo com a disponibilidade de frutos, áreas disponíveis para a coleta, quantidade de pessoas na família e com a safra. Isso pode ser comprovado nos discursos seguintes: "Conforme seja a safra, já cheguei até 1.000,00 por mês. [...] Conforme seja o tempo e a quantidade dos frutos. Já teve o dia de eu andar o dia todinho e não arranjar 5 litros." (C.10, 63 anos). "Na safra gira em torno de 800,00 por mês. Quando cai o período (Fora da safra) gira em torno de 400,00 a 500,00, muito sofrido, com muita luta." (C.5, 38 anos). Em Sergipe, essa atividade corresponde a $60 \%$ da renda familiar anual (SANTOS e SOUZA, 2016). Já a extração do pequi corresponde a $\mathrm{R} \$ 900,00$, em média, por família/safra (GAMA et al., 2017).

Outro aspecto importante é que a renda gerada no extrativismo da mangaba é uma renda majoritariamente feminina, expressando às relações de gênero no meio rural. Eventualmente, mesmo que o homem gere $60 \%$ da renda familiar, estudos sugerem que a renda feminina é muito mais efetiva em termos de segurança alimentar e manutenção de modo de vida, por exemplo, do que a renda masculina pelos usos destinados ao dinheiro. Logo, no contexto das relações de gênero, as mulheres tendem a fazer uso mais efetivo de um recurso relativamente pequeno destinado à família, assim, evitando desperdícios e usos inadequados (LAVINAS et al., 2012).

Vale salientar que, nas últimas décadas, as organizações das mulheres rurais, como o Movimento das Mulheres Camponesas (MMC), que lutam por terra e reconhecimento profissional, têm constantemente questionado as relações de gênero e poder no meio rural (FISCHER, 2010). O motivo para tais indagações inclui a visibilidade e importância da participação efetiva da mulher no cotidiano da produção e reprodução familiar, pois, apesar da invisibilidade do trabalho feminino no campo, na atualidade evidencia-se a presença e atuação das mulheres na produção agrícola e na conversão desses produtos em gêneros alimentícios (MENDES et al., 2014).

O extrativismo da mangaba apresenta grande potencial socioeconômico para as comunidades extrativistas, além de constituir uma alternativa para o fortalecimento da economia local. Todavia, acredita-se que o retorno econômico para os extratores e para outros segmentos envoltos na atividade poderia ser maior caso fossem instituídos: acesso aos locais de coleta com estabelecimento de acordos sociais entre os donos de terras e os coletores, manejo adequado das mangabeiras, melhoria nas condições de beneficiamento e processamento dos frutos, agregação de valor ao produto, políticas públicas de incentivo e viabilização de mercado consumidor garantido (OLIVEIRA e ALOUFA, 2019).

Conforme os entrevistados, integrar a renda total familiar através de PFNMs tem sido uma realidade para alguns atores envolvidos com essa atividade: "É uma coisa grande, porque é um emprego pra nós [...], mas quando, acaba, acabou tudo, é do que se vive aqui... É fonte de renda da gente". (C22, 29 anos). "Representa muita coisa, tem muita importância, não só pra mim, pra todos, é uma ajuda grande pra gente. É uma dificuldade grande pra ir buscar também, mas agradeço muito a Deus quando tem [...] É um trabalho pra gente aqui na Boa Água, porque emprego não tem não." (C21, 48 anos). Gama et al. (2017) constataram que o extrativismo do cambuí em Ribeira do Pombal-Bahia é uma forma complementar de renda para a população do município e região, e mesmo não sendo a renda principal, é

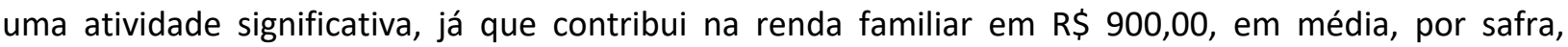
superando outros produtos extrativistas tradicionalmente comercializados e mais conhecidos no mercado. 
Quando questionados sobre a importância da mangaba para a região, todos os entrevistados remeteram aos benefícios econômicos do extrativismo. Além dessa percepção, foram citados os benefícios para alimentação humana e o ambiental. Conforme discursos relatados: "Ela é o pão de cada dia, porque tem muita gente passando necessidade aqui, tem muita gente pobre... o meio de vida aqui é a mangaba, o sustento da comunidade aqui é a mangaba e, quando falta, é muita gente sofrendo [...]." (C.1, 69 anos). "É porque ela dá um fruto bom, faz sombra, pra mim, ela representa coisa boa." (C.11, 58 anos). Nesse aspecto, verifica-se que o sistema agroextrativista da mangaba possibilita a inserção produtiva de famílias camponesas, melhorando sua qualidade de vida e, concomitantemente, atua reduzindo os impactos ambientais. Carrazza $(2009$, p. 270$)$ corrobora essa visão ao afirmar que:

[...] o agroextrativismo é um modelo de produção familiar que combina a coleta e o aproveitamento da biodiversidade nativa com a produção agrícola e pecuária. Acontece a partir do uso de tecnologias apropriadas e é focado na subsistência com excedente direcionado para o mercado. Tem sua viabilidade econômica e ambiental associada à diversificação da produção. Representa um modelo efetivo de fixação rural que concilia conservação ambiental com inclusão social e melhoria de qualidade de vida para as comunidades envolvidas e para a população como um todo.

Embora haja o reconhecimento por parte dos coletores em relação aos benefícios do extrativismo, um dos grandes problemas que enfrentam é o acesso limitado aos locais para a efetivação da prática extrativista. A privatização das áreas na região tem intensificado os desmatamentos para a construção civil, inclusive para evitar a entrada dos coletores nas propriedades. Conforme Brito e Mota (2010), um dos fatores que pode estar contribuindo para esse cenário é a falta de organização desses grupos, que gera a invisibilidade deles e dificulta a ação de políticas públicas que assegurem seus meios de vida. No caso das comunidades de Timbó, Boa Água e Bonfim, a maioria não possui terras para o cultivo da mangaba e dos que têm granjas, poucos conservam a espécie, logo, a melhor forma de proteger esses recursos é subsidiando o seu uso e manejo sustentável. Isso torna-se possível, uma vez que o extrativismo da mangaba além de promover benefícios para a geração de renda, atua na conservação do meio ambiente e na manutenção da prática cultural, constituída ao longo das gerações (OLIVEIRA, 2016).

O extrativismo da mangaba se destaca por ser uma atividade com potencial para o desenvolvimento sustentável do município de Nísia Floresta- RN. Porém, necessita de estratégias que integre a conservação dos recursos genéticos e culturais, como programas de capacitação organizacional para o beneficiamento da mangaba e implantação de uma associação para valorização do produto (OLIVEIRA e ALOUFA, 2019). Além disso, são necessárias ações integradas de órgãos públicos e comunidades envolvidas para auxiliar na manutenção das áreas remanescentes de mangabeira e a criação de uma associação que ampare as pessoas que utilizam o extrativismo como fonte de renda e meio de sustento.

Por fim, este estudo traz como reflexão o fato de que a privatização das áreas antes frequentadas pelos coletores, a redução das áreas remanescentes de mangabeira e o aumento da demanda pelos frutos têm causado maior exploração desses recursos. Esse fenômeno, sem um planejamento adequado, pode impulsionar à insustentabilidade do extrativismo de PFNM, como a mangaba. Portanto, destaca-se a necessidade de criação de novas possibilidades de uso dos recursos naturais através de técnicas aprimoradas e sustentáveis, que atendam aos princípios da Agroecologia, que tem seu papel fundamental no desenvolvimento da agricultura familiar camponesa (SILVA e FAGUNDES, 2011). E, que inclua a segurança alimentar e propicie a efetivação de estratégias participativas, que favoreçam a conservação do agroecossistema local.

\section{Conclusões}

O extrativismo da mangaba, no município de Nísia Floresta/RN, é uma atividade destituída de cadeia produtiva sistematizada, atuando através de conhecimentos tradicionais consolidados desde a coleta até a comercialização. O conhecimento e uso da mangaba estão bem difundidos nas três comunidades, tendo no extrativismo uma forma de complementação da renda familiar, com rendimento

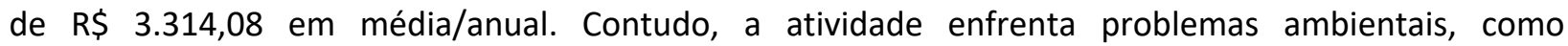


desmatamentos, queimadas, pouco reconhecimento do produto comercializado e falta de conhecimento dos benefícios do processamento dos frutos. Destarte, a criação de uma associação de catadores de mangaba no município, com apoio de órgãos públicos, pode ser uma alternativa para viabilizar a sustentabilidade da atividade, visando o fortalecimento das comunidades em práticas de bases ecológicas, ampliando a qualidade de vida das famílias envolvidas e, ainda, promover à conservação da biodiversidade.

\section{Agradecimentos}

Aos moradores das Comunidades de Timbó, Bonfim e Boa Água, que acolheram e colaboraram com nossa pesquisa. À Coordenação de Aperfeiçoamento de Pessoal de Nível Superior (CAPES), pela concessão de bolsa de pesquisa à primeira autora.

\section{Referências}

ALBUQUerque, U. P.; LUCENA, R. F. P.; CUNHA, L. V. F. C. Métodos e Técnicas na Pesquisa Etnobiológica e Etnoecológica. Recife: NUPEEA, 2010. 559p.

ALVES, R. V. Estudo de caso da comercialização dos produtos florestais não madeireiros (PFNM) como subsídio para restauração florestal. 2010. 211f. Dissertação (Mestrado em Ciência Florestal), Universidade Federal de Viçosa, Viçosa-MG, 2010.

ANDRADE, A. J. P.; SILVA, N. M.; SOUZA, C. R. As percepções sobre as variações e mudanças climáticas e as estratégias de adaptação dos agricultores familiares do Seridó potiguar. Desenvolvimento e Meio Ambiente, Curitiba-PR, v. 31, p. 77-96, 2014.

BRASIL. Lei $n^{\circ} \mathbf{1 2 . 6 5 1}$, de 25 de maio de 2012. Dispõe sobre a proteção da vegetação nativa; altera as Leis $n^{\circ} 6.938$, de 31 de agosto de 1981, 9.393, de 19 de dezembro de 1996, e 11.428, de 22 de dezembro de 2006; revoga as Leis nos 4.771, de 15 de setembro de 1965, e 7.754, de 14 de abril de 1989, e a Medida Provisória nº 2.166-67, de 24 de agosto de 2001; dá outras providências. Brasília: DOU de 21/5/2012.

BRITO, J. V. S.; MOTA, D. M. O Extrativismo da mangaba em Sergipe: uma atividade meramente feminina? In: VIII Congresso Latino-Americano de Sociologia Rural, 2010. Anais... Recife, UFRPE, 2010.

CARRAZZA, L. Tecnologias Sociais Agroextrativistas como Estratégia de conservação e Desenvolvimento Local. In: Tecnologias Sociais: Caminhos para a sustentabilidade. / Aldalice Otterloo [et al.]. - Brasília/DF: s. n., 2009. 278 p. (p.264-277).

DIAS, H. M.; SOARES, M. L. G.; NEFFA, E. Espécies florestais de restingas como potenciais instrumentos para gestão costeira e tecnologia social em Caravelas, Bahia (Brasil). Ciência Florestal, Santa Maria, v. 24, n. 3, p. 727-740, 2014. DUTRA, R. M. S.; SOUZA, M. M. O. Agroextrativismo e geopolítica da natureza: alternativa para o Cerrado na perspectiva analítica da cienciometria. Ateliê Geográfico, Goiânia, v. 11, n. 3, p. 110-133, 2017.

FACHINELLO, D. T. Produtos Florestais Não-Madeiráveis (PFNM) no Estado de Rondônia e as Visões sobre Desenvolvimento, Sustentabilidade e Extrativismo. 2010. 99 f. Dissertação (Mestrado em Administração) Programa de Pós-Graduação Mestrado em Administração - PPGMAD, Porto Velho: UNIR, 2010.

FISCHER, I. "Relações de gênero na agricultura familiar no acampamento de Sem Terra do Engenho Prado". In: SCOTT, P.; CORDEIRO, R. (Org.). Agricultura Familiar e Gênero: práticas, movimentos e políticas públicas. Recife: Editora Universitária da UFPE, 2010. p. 193-204.

FILDLER, N. C. et al. Produtos florestais não madeireiros: importância e manejo sustentável da floresta. Revista Ciências Exatas e Naturais, Paraná, v. 10, n.2, p.42-45, 2008.

FONTANELLA, B. J. B.; RICAS, J.; TURATO, E. R. Amostragem por saturação em pesquisas qualitativas em saúde: contribuições teóricas. Cadernos de Saúde Pública, v. 24, n.1, 17-27, 2008.

GAMA, D. C. et al. O cambuí (Myrciaria tenella (DC.) O. Berg; Myrtaceae): extrativismo e geração de renda em Ribeira do Pombal-Bahia. Rev. Bras. de Agroecologia, v. 12, n. 1, p. 42-51, 2017.

GIL, A. C. 2008. Métodos e técnicas de pesquisa social. 6. ed., São Paulo: Atlas 200 p.

IBGE. Instituto Brasileiro de Geografia e Estatística. Produção da Extração Vegetal e da Silvicultura. 2018. Rio de Janeiro: IBGE, 2018. Disponível em: <https://cidades.ibge.gov.br/brasil/rn/nisiafloresta/pesquisa/16/12705?ano=2018>. Acesso em: 23 mar. 2020.

Instituto de Defesa do Meio Ambiente-IDEMA. Perfil do seu município: Nísia Floresta. 2013. Disponível em:< http://adcon.rn.gov.br/ACERVO/idema/DOC/DOC000000000016676.PDF>

JESUS, N. B.; GOMES, L. J. G. Conflitos socioambientais no extrativismo da aroeira (Schinus terebebinthifolius Raddi), Baixo São Francisco - Sergipe/Alagoas. Ambiente \& Sociedade, São Paulo, v. 15, n. 3, p. 55-73, 2012. 
LAVINAS, L.; COBO, B.; VEIGA, A. Bolsa Família: impacto das transferências de renda sobre a autonomia das mulheres pobres e as relações de gênero. Revista Latinoamericana de Población, v. 6, n. 10, p. 31-56, 2012.

LIMA, I. L. P.; SCARIOT, A. Boas práticas de manejo para o extrativismo sustentável da Mangaba. Brasília: Embrapa Recursos Genéticos e Biotecnologia, 2010.

LIMA, I. L. P. et al. Diversidade e uso de plantas do Cerrado em comunidade de Geraizeiros no norte do estado de Minas Gerais, Brasil. Acta bot. bras., Belo Horizonte- MG, v. 26, n. 3, p. 675-684, 2012.

LINHARES, J.F.P.; PINHEIRO, C.U.B. Caracterização do sistema de extração de látex de janaúba (Himatanthus Willd. ex Schult. - Apocynaceae), no Município de Alcântara, Estado do Maranhão, Brasil. Rev. Pan-Amaz Saude, Pará, v. 4, n. 1, p. 23-31. 2013.

MACHADO, F. S. Manejo de Produtos Florestais Não-Madeireiros: um manual com sugestões para o manejo participativo em comunidades da Amazônia. Rio Branco: PESACRE e CIFOR, 2008. 105 p.

MENDES, M. F. et al. A organização das mulheres extrativistas na região Sudoeste mato-grossense, Brasil. Estudos Feministas, Florianópolis, v. 22, n. 1, p. 416, 2014.

MMA, Ministério do Meio Ambiente (2018). Bioma cerrado. Disponível em: http://www.mma.gov.br/biomas/cerrado. Consultado: 07/11/2018.

MORAES, T. M. et al. Hancornia speciosa: Indications of gastroprotective, healing and anti-Heliobacter pilori actions. Journal of Ethnopharmacology, v. 120, p. 161-168, 2008.

MOTA, D. M.; SANTOS, J. V. Uso e conservação dos remanescentes de mangabeira por populações extrativistas em Barra dos Coqueiros, Estado de Sergipe. Acta Sci. Human Soc. Sci. Maringá, v. 30, n.2, p.173-180, 2008.

OLIVEIRA, L. C. A.; VELASCO, D. G. Os saberes tradicionais da macaúba (Acrocomia aculeata) associados à feira agroecológica raízes do campo em Jaboticatubas, MG/Brasil. Revista Euroamericana de Antropología, n. 7, p. 135147, 2019.

OLIVEIRA, K. S. Comunidades extrativistas e o uso da biotecnologia vegetal como alternativa à conservação da mangabeira (Hancornia speciosa Gomes). 2016. 97p. Dissertação (Mestrado em Desenvolvimento e Meio Ambiente). Universidade Federal do Rio Grande do Norte, Natal-RN, 2016.

OLIVEIRA, D. M. et al. Identificação dos pontos críticos no sistema extrativista da mangaba (Hancornia speciosa Gomes) em Sergipe. Guaju, Matinhos, v. 3, n. 1, p. 11-36, 2017.

OLIVEIRA, K. S.; ALOUFA, M. A. I. Percepção ambiental e extrativismo da mangabeira: um estudo em comunidades do Rio Grande do Norte. Gestão e sustentabilidade ambiental, Florianópolis, v. 8, n. 4, p. 420-442, 2019.

PRIMACK, R. B; RODRIGUES, E. Biologia da Conservação. Londrina: Editora Planta, 2006. 327p.

RITTER, M. R. et al. Plantas usadas como medicinais no município de Ipê, RS, Brasil. Ver. Bras. Framacogn, v12, p.5162, 2002.

SANTOS, J. V. O papel das mulheres na conservação das áreas remanescentes de mangabeiras (Hancornia speciosa Gomes) em Sergipe. 2007. 103 f. Dissertação (Mestrado em Agroecossistemas). Universidade Federal de Sergipe, São Cristóvão, 2007.

SANTOS, E. A.; SOUZA, R. M. Territorialidade das catadoras de mangaba no litoral sul de Sergipe. Geosaberes, Fortaleza, v. 6, n. 3, p. 629-642, 2016.

SARAIVA, R. M.; JESUS, S. M. S. A.; SILVA, A. S. As catadoras de mangaba e o seu papel no contexto da sociedade sergipana. In: VI Colóquio Internacional “Educação e contemporaneidade”, São Cristóvão/SE, 2012.

SILVA, C. G. et al. Hancornia speciosa Gomes induces hypotensive effect through inhibition of ACE and increase on NO. Journal of Ethnopharmacology, v. 137, p. 709-711, 2011.

SILVA, C. V.; MIGUEL, L. A. Extrativismo e abordagem sistêmica. Novos Cadernos NAEA, v. 17, n. 2, p. 189-217, 2014. SILVA, M. E. C. et al. Aspectos etnobotânicos da palmeira babaçu (Attalea speciosa Mart. ex Spreng.) em comunidades extrativistas no Piauí, nordeste do Brasil. Gaia Scientia, v. 11, n. 3, p. 196-211, 2017.

SHIRAISHI NETO, J. Quebradeiras de coco: "babaçu livre" e reservas extrativistas. Veredas do Direito, Belo Horizonte, v.14, n.28, p.147-166, 2017.

SOUSA, R. P. Agroecologia e educação do campo: desafios da institucionalização no Brasil. Educ. Soc., Campinas, v. 38, n. 140, p.631-648, 2017.

TOLEDO, V. M.; BARRERA-BASSOLS, N. A memória biocultural: a importância ecológica das sabedorias tradicionais. São Paulo: Expressão Popular, 2015.

VIEIRA, M. C. et al. Mangabeira (Hancornia speciosa Gomes): uma frutífera promissora do Brasil. Scientific Electronic Archives, Mato Grosso, v. 10, n. 2, 2017. 